\title{
The endocrine vitamin D system in the gut
}

Antonio Barbáchano, Asunción Fernández-Barral, Gemma Ferrer-Mayorga, María Jesús Larriba, Alberto Muñoz ${ }^{*}$

Instituto de Investigaciones Biomédicas “Alberto Sols”, Consejo Superior de Investigaciones Científicas - Universidad Autónoma de Madrid, E-28029 Madrid, Spain

*Corresponding author. Instituto de Investigaciones Biomédicas “Alberto Sols”, Arturo Duperier, 4, E-28029 Madrid, Spain

E-mail address: amunoz@iib.uam.es

Telephone: (+34) 915854451; Fax: (+34) 915854401 


\section{ABSTRACT}

The active vitamin $\mathrm{D}$ metabolite $1 \alpha, 25$-dihydroxyvitamin $\mathrm{D}_{3}\left(1,25(\mathrm{OH})_{2} \mathrm{D}_{3}\right)$ has important regulatory actions in the gut through endocrine and probably also intracrine, autocrine and paracrine mechanisms. By activating the vitamin D receptor (VDR), which is expressed at a high level in the small intestine and colon, $1,25(\mathrm{OH})_{2} \mathrm{D}_{3}$ regulates numerous genes that control gut physiology and homeostasis. $1,25(\mathrm{OH})_{2} \mathrm{D}_{3}$ is a major responsible for epithelial barrier function and calcium and phosphate absorption, and the host's defense against pathogens and the inflammatory response by several types of secretory and immune cells. Moreover, recent data suggest that $1,25(\mathrm{OH})_{2} \mathrm{D}_{3}$ has a regulatory effect on the gut microbiota and stromal fibroblasts. Many studies have linked vitamin D deficiency to inflammatory bowel diseases (ulcerative colitis and Crohn's disease) and to an increased risk of colorectal cancer, and the possible use of VDR agonists to prevent or treat these diseases is receiving increasing interest.

Keywords: Vitamin D; Gut Homeostasis; Inflammatory Bowel Diseases; Gut Microbiota; Colorectal Cancer; Thyroid Hormone. 


\section{Introduction}

For a long time, the gut has been known to be a major target tissue of vitamin D. $1 \alpha, 25$ dihydroxyvitamin $\mathrm{D}_{3}\left(1,25(\mathrm{OH})_{2} \mathrm{D}_{3}\right)$, the hormonal vitamin $\mathrm{D}$ metabolite from the bloodstream (endocrine action) or locally produced from circulating $25(\mathrm{OH}) \mathrm{D}_{3}$ within intestinal cells expressing the enzyme $25(\mathrm{OH}) \mathrm{D}_{3}-1 \alpha$-hydroxylase/cytochrome $\mathrm{P}_{450}$ CYP27B1 (intracrine, autocrine and paracrine action), is a critical regulator of gut physiology and homeostasis (Figure 1). $1,25(\mathrm{OH})_{2} \mathrm{D}_{3}$ is crucial for $\mathrm{Ca}^{2+}$ and phosphate absorption and for epithelial integrity/barrier function and it contributes to detoxification and protection against infection (Christakos et al., 2016). Accordingly, the high affinity vitamin D receptor (VDR), a predominantly nuclear protein that regulates gene expression, is expressed in the small and large intestine/colon by epithelial and fibroblastic cells and by B-lymphocytes, T-lymphocytes (CD4 ${ }^{+}$and $\mathrm{CD}^{+}$), macrophages and dendritic cells (Veldman et al., 2000). Remarkably, VDR levels are higher in intestinal epithelial cells than in other tissues and cell types (Yamamoto et al., 1999). All intestinal cell types also express CYP27B1, which supports intracrine, autocrine or paracrine effects of $1,25(\mathrm{OH})_{2} \mathrm{D}_{3}$ (Adams and Hewison, 2008; Kundu et al., 2014). $1,25(\mathrm{OH})_{2} \mathrm{D}_{3}$ is one of the main regulators of the human genome controlling the transcription rate of hundreds of genes in a tissue-specific fashion via its binding and modulation of VDR activity, as a transcription factor within the cell nucleus and as an inducer of non-genomic signaling in the cytosol (OrdonezMoran et al., 2008). Thus, the effects of $1,25(\mathrm{OH})_{2} \mathrm{D}_{3}$ in the gut are mediated by the proteins encoded by its target genes, a significant proportion of which are specific to this organ.

The importance of $1,25(\mathrm{OH})_{2} \mathrm{D}_{3}$ action in the gut is supported by the association of multiple pathologies with vitamin $\mathrm{D}$ deficiency, such as loss of $\mathrm{Ca}^{2+}$ homeostasis 
(rickets and osteomalacia), inflammatory bowel diseases (IBD: ulcerative colitis and Crohn's disease) and increased risk of colorectal cancer (CRC) (Figure 2). Mice lacking $\operatorname{Vdr}\left(V_{d r}^{-/}\right)$develop hypocalcemia and hypophosphatemia and severe bone malformation together with other defects, but no gross abnormalities in the gut. However, these $\mathrm{Vdr}^{-/-}$mice show high levels of markers of cell proliferation and DNA oxidative damage in the colon (Kallay et al., 2002).

\section{2. $\mathrm{Ca}^{2+}$ and phosphate absorption}

Control of $\mathrm{Ca}^{2+}$ homeostasis in the organism is the most classical and probably the principal role of $1,25(\mathrm{OH})_{2} \mathrm{D}_{3}$. In conditions of low $\mathrm{Ca}^{2+}$, high level of $1,25(\mathrm{OH})_{2} \mathrm{D}_{3}$ is generated from $25(\mathrm{OH}) \mathrm{D}_{3}$, due to induction of CYP27B1 in the kidney by the action of parathyroid hormone. Conversely, high $\mathrm{Ca}^{2+}$ inhibits $1,25(\mathrm{OH})_{2} \mathrm{D}_{3}$ synthesis, as does a high level of $1,25(\mathrm{OH})_{2} \mathrm{D}_{3}$ itself. As mentioned above, gut epithelial and immune cells also express CYP27B1, and thus synthesize $1,25(\mathrm{OH})_{2} \mathrm{D}_{3}$ that acts intracrinally, autocrinally and/or paracrinally on neighbour cells. The homeostatic action of $1,25(\mathrm{OH})_{2} \mathrm{D}_{3}$ on $\mathrm{Ca}^{2+}$ occurs in bone, kidney and, above all, in the intestine, where $1,25(\mathrm{OH})_{2} \mathrm{D}_{3}$ is essential for $\mathrm{Ca}^{2+}$ absorption in basically all segments. It induces saturable transcellular transport, predominantly in the proximal small intestine (duodenum, jejunum), and nonsaturable paracellular transport. The mechanism of these two transport systems and of several key genes (TRPV6, calbindin D9K, PMCA1, alkaline phosphatase I/ALPI, claudin-2, claudin-12, cadherin-17 and aquaporin-8, among others) mediating them are detailed in the article by J. Fleet in this issue and in recent reviews (Christakos et al., 2016). Interestingly, a recent study by Lee and colleagues (Lee et al., 2015) has revealed a global network of genes in the mouse proximal intestine that are involved in $\mathrm{Ca}^{2+}$ absorption. These include previously known 
genes and a cohort of novel $1,25(\mathrm{OH})_{2} \mathrm{D}_{3}$ target genes, some of which may be controlled by this hormone in the intestine independently from $\mathrm{Ca}^{2+}$ homeostasis.

$1,25(\mathrm{OH})_{2} \mathrm{D}_{3}$ also contributes to regulating phosphate homeostasis, again through actions in the bone (increasing FGF23 expression) and the kidney (modulating reabsorption in the proximal tubules), together with the induction of phosphate uptake in the gut. As in the case of $\mathrm{Ca}^{2+}$, a low phosphate diet increases circulating $1,25(\mathrm{OH})_{2} \mathrm{D}_{3}$, and phosphate uptake combines active transport and passive diffusion. However, the effect of $1,25(\mathrm{OH})_{2} \mathrm{D}_{3}$ on phosphate absorption is less important than its

effect on $\mathrm{Ca}^{2+}$ (perhaps because the human diet is usually rich in phosphate and intestinal absorption is mostly paracellular), and much less is understood about the mechanism of action, which in rats involves the apical membrane sodium-phosphate cotransporter NaPi IIb (see also the article by Fleet and cols. in this issue).

\section{Epithelial cell differentiation: the barrier function}

A fundamental characteristic of the differentiated intestinal epithelium is the establishment of a barrier to the free exchange of molecules between the internal milieu of the organism and the external medium, the intestinal lumen. This barrier also provides protection against infection by microorganisms. It is constituted by a series of adhesion structures between adjacent epithelial cells, which from apical to basal domains are: tight junctions, adherens junctions, desmosomes and gap junctions. Mucosal transepithelial resistance (TER) is an indicator of mucosal permeability and barrier integrity. Disruption of the barrier function takes place during inflammation and bacterial infection causing colitis and facilitating the entry of microorganisms into the intestinal tissue. As discussed in the following sections, altered barrier function is linked to abnormalities in the immune response and thus to IBDs. 
$1,25(\mathrm{OH})_{2} \mathrm{D}_{3}$ upregulates tight junctions proteins (occludin, zonula occludens (ZO)-1 and -2, and claudin-2, -7 and -12) and adherens junctions proteins (E-cadherin) (Pálmer et al., 2001; Fujita et al., 2008; Zhao et al., 2012), and thus contributes to maintaining the differentiated adhesive phenotype of intestinal epithelial cells. Concordantly, 1,25(OH) ${ }_{2} \mathrm{D}_{3}$ increases TER in cultured cells (Pñalmer et al., 2001; Kong et al., 2008; Zhao et al., 2012), while a lack of $V d r$ markedly reduces TER in experimental colitis mouse models (Froicu et al., 2003; Kong et al., 2008; Liu et al., 2013).

Tumor necrosis factor (TNF)- $\alpha$ controls intestinal epithelial barrier through the regulation of tight junctions. It increases the permeability of human colon carcinoma cell monolayers at least in part by inducing the long isoform of myosin light chain kinase (MLCK) and myosin II regulatory light chain phosphorylation. $1,25(\mathrm{OH})_{2} \mathrm{D}_{3}$ protects against TNF- $\alpha$-induced injury of the intestinal barrier by suppressing the MLCK pathway in cultured HCT116, CaCo-2 and SW480 cells (Du et al., 2015). This effect is mediated by the inhibition of nuclear factor kappa B (NFkB) binding to the promoter of the $M L C K$ gene and is reproduced by the $1,25(\mathrm{OH})_{2} \mathrm{D}_{3}$ analogue paricalcitol in a mouse model of colitis (Du et al., 2015). Likewise, $1,25(\mathrm{OH})_{2} \mathrm{D}_{3}$ restores tight junction integrity upon injury induced by bacterial lipopolysaccharide in CaCo-2 cells (Chen et al., 2015). Additionally, $1,25(\mathrm{OH})_{2} \mathrm{D}_{3}$ maintains mucosal barrier integrity by blocking intestinal cell apoptosis induced by TNF- $\alpha-N F \kappa B-P U M A$ during inflammation (Liu et al., 2013; Liu et al., 2015).

$1,25(\mathrm{OH})_{2} \mathrm{D}_{3}$ increases the expression and/or activity of several brush border enzymes that are considered differentiation markers in the small intestine, such as alkaline phosphatase and maltase, and enhances the formation of microvilli (Brehier and Thomasset, 1988; Halline et al., 1994; Chen et al., 1999). The effect on alkaline 
phosphatase seems to be mediated by the transcription factor activator protein-1 (Chen et al., 1999). In CRC cells $1,25(\mathrm{OH})_{2} \mathrm{D}_{3}$ increases the expression of a plasma membrane calcium ATPase isoform associated with differentiation (Ribiczey et al., 2015), while the short-chain fatty acid butyrate enhances VDR expression and the prodifferentiation action of $1,25(\mathrm{OH})_{2} \mathrm{D}_{3}$ evaluated by analyzing the activity of alkaline phosphatase (Gaschott and Stein, 2003). Likewise, 17 $\beta$-estradiol and certain phytoestrogens increase VDR and CYP27B1 expression while they reduce that of CYP24A1, the enzyme that degrades $1,25(\mathrm{OH})_{2} \mathrm{D}_{3}$, in cultured CRC cells and in the rodent colon. This may be one of the beneficial effects of estrogens in the gut (Schwartz et al., 2000; Gilad et al., 2006).

The importance of $1,25(\mathrm{OH})_{2} \mathrm{D}_{3}$ in gut biology is further supported by its relation with CDX-2. CDX-2 is a homeodomain transcription factor that mediates intestinal differentiation and has a key role in intestinal development and in homeostasis in adult life (Beck et al., 1999; Gao et al., 2009). CDX-2 expression is linked to the differentiation (polarization and adhesive phenotype) of human CaCo-2 colon adenocarcinoma cells (Pereira et al., 2013). Although it is rarely mutated in CRC, CDX2 downregulation is frequent in CRC (and other neoplasias of the digestive tract) and is associated with poor tumor differentiation (Brabletz et al., 2004). Therefore, it is considered a tumor suppressor gene in CRC (Bonhomme et al., 2003). Interestingly, CDX-2 protein binds the human VDR gene promoter and induces its transcription in CaCo-2 cells (Yamamoto et al., 1999). Moreover, a polymorphism (A>G) in the CDX-2 binding site of the $V D R$ promoter ( $C d x 2$ polymorphism) affects $V D R$ transcription and activity, and is associated with the risk of several cancers including CRC (Pulito et al., 2015; Serrano et al., 2016). These data indicate that $1,25(\mathrm{OH})_{2} \mathrm{D}_{3} / \mathrm{VDR}$ may mediate part of the crucial effects of CDX-2 on gut biology. 


\section{Anti-inflammatory and anti-infectious actions. Inflammatory bowel diseases}

In line with the expression of VDR in most types of immune cells, $1,25(\mathrm{OH})_{2} \mathrm{D}_{3}$ regulates both the innate (positively) and the adaptive (negatively in situations of over/autoreactivity) immune response (Adams and Hewison, 2008) (see also the articles by J. White and by A. Verstuyf and C. Mathieu in this issue). In the gut, these actions of $1,25(\mathrm{OH})_{2} \mathrm{D}_{3}$ translate into important anti-inflammatory and anti-infectious effects in experimental systems, including: synthesis of antimicrobial defensive peptides (cathelicidin/LL-37, $\beta$-defensin); regulation of the differentiation, trafficking and secretion of cytokines by immune cells; and preservation of the gut barrier function. Accordingly, a series of studies have proposed that vitamin D deficiency could be associated with chronic inflammation and autoimmune disorders (Krishnan and Feldman, 2010; Cantorna et al., 2014; Meeker et al., 2014; Cai et al., 2015; van HartenGerritsen et al., 2015; Meeker et al., 2016). Epidemiological studies indicate that vitamin D deficiency is associated with, and deleterious to, clinical conditions linked to immune imbalances and chronic inflammation such as ulcerative colitis (most frequently affecting the rectum) and Crohn's disease (generally affecting the terminal ileum) (Yu et al., 2008; Meckel et al., 2016).

However, the causality of this association is a matter of debate (Autier et al., 2014; Mangin et al., 2014) and the protective effects of supplementation with vitamin $\mathrm{D}, 1,25(\mathrm{OH})_{2} \mathrm{D}_{3}$ or other VDR agonists on inflammatory or autoinmmune diseases such as IBDs have not been demonstrated unequivocally. Hypovitamin D status has been linked to higher risk of CRC, and particularly to chronic inflammation-associated CRC, which may occur in long-term ulcerative colitis and Crohn's disease patients (Wada et al., 2009). In addition, vitamin D supplementation decreased symptoms in a pilot study 
in Crohn's patients (Yang et al., 2013), and higher predicted plasma 25(OH)D levels significantly reduced the risk of Crohn's disease (Ananthakrishnan et al., 2012). Moreover, as in other diseases, vitamin D deficiency has a negative effect on the action of other therapies (i.e., anti-TNF- $\alpha$ in ulcerative colitis patients) (Zator et al., 2014).

Deletion of $V d r$ or vitamin D deficiency in mice does not cause IBD but increases inflammation and predisposes to and enhances the severity of the disease. Concordantly, expression of human VDR in intestinal epithelial cells of mice defective for interleukin (IL)-10 attenuates the development of spontaneous colitis in these animals (Golan et al., 2015). Mice lacking Vdr display chronic inflammation, with reduced CD4/CD8 $\alpha \alpha$ intraepithelial lymphocytes and decreased homing of $\mathrm{T}$ cells to the gut (Yu et al., 2008). Interestingly, a recent study has shown that deletion of $V d r$ in the epithelial intestine downregulates the expression of lysozyme and ATG16L1, which causes defective autophagy, impairs the antimicrobial function of Paneth cells and increases susceptibility to experimental colitis (Wu et al., 2015).

In a number of systems, the anti-inflammatory action of $1,25(\mathrm{OH})_{2} \mathrm{D}_{3}$ is based on its multilevel repressing effect on $\mathrm{NF} \kappa \mathrm{B}$, a transcription factor that controls many genes involved in the immune response and inflammation. $1,25(\mathrm{OH})_{2} \mathrm{D}_{3}$ decreases the

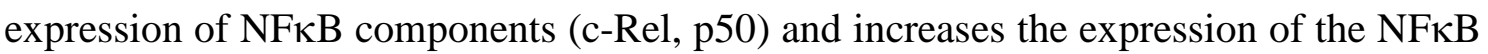


transcriptional activity ( $\mathrm{Yu}$ et al., 1995; Bao et al., 2006). As a consequence, $1,25(\mathrm{OH})_{2} \mathrm{D}_{3}$ downregulates the expression of pro-inflammatory cytokines such as TNF- $\alpha$ and several interleukins (IL-1 $\beta$, IL-6, IL-8 and others), chemokines (CCL2 and others), and cyclooxygenase-2, the enzyme responsible for prostaglandin synthesis. Consistently, this NFkB-induced program is enhanced in mice lacking $V d r$, which are also more susceptible to bacterially and chemically induced colitis (Liu et al., 2013). In 
line with these data, a recent study has shown that $1,25(\mathrm{OH})_{2} \mathrm{D}_{3}$-deficient mice due to the lack of the Cyp27b1 gene display a colon inflammatory phenotype with shortened colon length, abnormal mucosal structure, and inflammatory cell infiltration accompanied by increased reactive oxidative species and DNA damage, cellular senescence and production of senescence-associated inflammatory cytokines (Liu et al., 2016).

Conversely, hypovitamin D status and low VDR expression may be a consequence of local inflammation or infection, rather than the cause (Mangin et al., 2014). Supporting this view, TNF- $\alpha$ reduces VDR levels by inducing microRNA (miR)346 that targets VDR mRNA (Chen et al., 2014), and patients with ulcerative colitis and Crohn's disease show reduced levels of VDR in the intestinal epithelium ( $\mathrm{Li}$ et al., 2013). Conceivably, the resulting situation in vivo will depend on the intensity of the two opposite signals: the anti-inflammatory action of $1,25(\mathrm{OH})_{2} \mathrm{D}_{3}$ and the inflammation-based effects that repress VDR expression and function.

In summary, $1,25(\mathrm{OH})_{2} \mathrm{D}_{3} / \mathrm{VDR}$ modulates inflammation and infection, which are interrelated critical factors for intestinal homeostasis whose deregulation is implicated in the pathogenesis of IBDs. A deficient $1,25(\mathrm{OH})_{2} \mathrm{D}_{3} / \mathrm{VDR}$ system does not cause IBDs per se but available data suggest that it may contribute to their development as an important regulator of the intestinal immune system and the epithelial barrier function.

\section{Relation with the intestinal microbiota}

Intestinal microbiota is another important factor in IBDs together with genetics, environment, and inflammation (Frank et al., 2007). Damaged intestinal mucosa may facilitate microbial translocation that in turn may alter the local immune system. 
Moreover, the intestinal microbiota may also affect systemic diseases (including diabetes and rheumatoid arthritis), CRC and the gut-brain axis (Qin et al., 2012; Nakatsu et al., 2015; Giloteaux et al., 2016; Obata and Pachnis, 2016)

Mutual, ill-defined interactions exist between vitamin D and the normal and pathological microbiota. Vitamin D not only regulates the immune response to the microbiota but also changes the gut microbiota (dysbiosis); an effect that is mediated by the host as bacteria lack VDR (Ooi et al., 2013; Cantorna et al., 2014). In mice, vitamin D deficiency at birth causes lower numbers of colonic Bacteroides and Prevotella later in life (Jahani et al., 2014). Mice lacking Vdr have reduced amounts of bacteria from the Firmicutes phylum and increased amounts from the Bacteroides and the Proteobacteria phyla in the feces (Ooi et al., 2013), and changes in several bacterial genus members including Eubacterium, Bacteroides and Salmonella are also observed between $V d r^{-/-}$ and wild-type mice (Chen et al., 2015). In addition, Jin et al. have reported that a lack of $V d r$ in mice not only causes dysbiosis, with depletion of Lactobacillus and enrichment of Clostridium and Bacteroides in the fecal stool and depletion of Alistipes and Odoribacter and enrichment of Eggerthella in the cecal stool, but also leads to changes in important pathways of the intestinal microbiota that together can potentially affect detoxification, infection, cancer and other diseases (Jin et al., 2015). Curiously, treatment with $1,25(\mathrm{OH})_{2} \mathrm{D}_{3}$ has been proposed to increase Citrobacter rodentium load in the colon and spleen of mice probably through suppression of the Th17 response (Ryz et al., 2012), while a vitamin D-deficient diet aggravated barrier dysfunction, dysbiosis and inflammation following infection with bacteria (Assa et al., 2015), and a lack of $V d r$ augmented IL-22-producing innate lymphoid cells causing dysbiosis and resistance to colonization by Citrobacter rodentium (Chen et al., 2015). 
There is a dynamic interplay between bacteria and VDR expression in the gut. On the one hand, $V d r^{-/-}$mice express less I $\mathrm{B} \mathrm{B} \alpha$ and so have increased basal and bacteria-induced NFאB activity and inflammation, together with fewer Paneth cells in the ileum and higher bacterial load in the intestinal mucosa (see (Wu et al., 2015) and references therein). Remarkably, immune alterations caused by Vdr deficiency in mice lead to IBD-like unregulated inflammation in response to normally non-pathogenic bacteria and increased sensitivity to Salmonella-induced colitis (Yu et al., 2008; Wu et al., 2015). Moreover, probiotic treatment (Lactobacillus rhamnosus strain GG and Lactobacillus plantarum) increases VDR protein and the expression of target genes in human and mouse intestinal epithelial cells, and confers protection against Salmonellainduced colitis in wild-type mice but not in $V d r^{-/-}$mice (Wu et al., 2015). Based on these results, these authors suggest that the variable response to probiotics and clinical outcomes of IBD patients may partly be due to the status of their $1,25(\mathrm{OH})_{2} \mathrm{D}_{3} / \mathrm{VDR}$ system. Interestingly, butyrate, which is a fermentation product of gut microbes that increases intestinal VDR expression, attenuates basal and TNF- $\alpha-$ and lipopolysaccharide-induced NFאB activity in human HT-29 colon carcinoma cells and suppresses inflammation in a colitis model (Schwab et al., 2007). However, several studies have found that some pathogenic bacteria and other microorganisms downregulate Vdr expression (Mangin et al., 2014), while increased expression and relocation of Vdr in the colon by pathogenic bacteria has also been reported (Sun et al., 2008).

Data in humans are very scarce. In a double-blind, placebo-controlled, randomized, parallel-arm, multicenter study, oral supplementation with probiotic Lactobacillus reuteri NCIMB 30242 increased circulating 25(OH)D levels relative to placebo (Jones et al., 2013). Notably, in a study in African American males, the level of 
circulating 25(OH)D was associated with differences in stool microbial composition: a decrease in the relative abundance of Roseburia, Blautia, Ruminococcus and Dorea (Firmicutes phylum, Clostridia class) was found in individuals with higher 25(OH)D concentration (Ciubotaru et al., 2015). Clearly, much work is needed to define the crosstalk between the vitamin D system and intestinal microbiota. However, available data suggest a complex mutual relation that may contribute to intestinal homeostasis.

\section{Intestinal fibroblasts}

The effect of $1,25(\mathrm{OH})_{2} \mathrm{D}_{3}$ on intestinal fibroblasts has only recently begun to be investigated. In a mouse model of chronic colitis, vitamin D inhibits intestinal fibrosis induced by administration of 2,4,6-trinitrobenzene through the reduction of the TGF- $\beta 1$ dependent stimulation of collagen I synthesis and extracellular matrix deposition by colonic subepithelial myofibroblasts (Tao et al., 2015). In humans, our group has reported that normal colon fibroblasts derived from healthy colonic tissue obtained from biopsies of CRC patients express VDR and respond to $1,25(\mathrm{OH})_{2} \mathrm{D}_{3}$. Thus, $1,25(\mathrm{OH})_{2} \mathrm{D}_{3}$ treatment regulates the expression of around one thousand genes in these cells that are involved in a large series of cellular functions: adhesion, migration, wound healing and matrix remodeling, chemokine production and inflammatory response (Ferrer-Mayorga et al., 2016). Moreover, $1,25(\mathrm{OH})_{2} \mathrm{D}_{3}$ reduces the capacity of these cells to contract collagen gels and to induce the migration of colon carcinoma cells; two hallmarks of protumoral fibroblastic activation (Ferrer-Mayorga et al., 2016). These results indicate a homeostatic effect of $1,25(\mathrm{OH})_{2} \mathrm{D}_{3}$ at the level of intestinal fibroblasts.

\section{Detoxification}


Global transcriptomic studies have revealed that $1,25(\mathrm{OH})_{2} \mathrm{D}_{3}$ regulates the expression of several antioxidant ( $\gamma$-glutamyl transpeptidase, glutathione peroxidase, Pi-class glutathione S-transferases, epoxide hydrolase), Phase I (CYP1A1, CYP3A1, CYP3A3, CYP4F5, CYP2B2, CYP3A9, 3 $\alpha$ - and 17 $\beta$-hydroxysteroid dehydrogenases) and Phase II (UDP-glucuronosyltransferases and sulfotransferases) enzymes, which are involved in the chemical modification and elimination of toxic compounds in the rat intestinal lumen (Kutuzova and DeLuca, 2007) and in cultured human colon carcinoma cells (Pálmer et al., 2003; Tachibana et al., 2009).

Lithocholic acid (LCA) is a secondary bile acid that has deleterious effects in colonic cells, where it induces DNA damage and inhibits DNA repair enzymes. Remarkably, LCA binds (with lower affinity than $1,25(\mathrm{OH})_{2} \mathrm{D}_{3}$ ) and activates VDR (Makishima et al., 2002). In intestinal cells, this induces the expression of CYP3A4, a drug-metabolizing enzyme; SULT2A1 sulfotransferase; and MRP3, a multi-drug resistance-associated protein (Chatterjee et al., 2005; Jurutka et al., 2005; McCarthy et al., 2005; Fukumori et al., 2007; Matsubara et al., 2008; Fan et al., 2009). As CYP3A4, SULT2A1 and MRP3 are involved in the elimination of LCA, this is a feedback mechanism to eliminate the highly toxic LCA from the colon.

Altogether, these results indicate that $1,25(\mathrm{OH})_{2} \mathrm{D}_{3}$ is a xenobiotic sensor and contributes to the detoxification process in the intestine by controlling the expression of enzymes involved in the catabolism of xenobiotics, steroids, bile acids and other compounds.

\section{Colorectal cancer}

In concordance with its homeostatic actions in the healthy intestine, a large number of epidemiological and preclinical studies support a protective role of vitamin D against 
CRC. Thus, several meta-analyses indicate that vitamin D deficiency is associated with increased CRC incidence, progression, and/or mortality (Giovannucci, 2013; Tagliabue et al., 2015; Jacobs et al., 2016). Studies in animals (xenografted tumors, chemicallyinduced carcinogenesis, genetic models for CRC and Vdr-deficient mice) and cultured cells show that $1,25(\mathrm{OH})_{2} \mathrm{D}_{3}$ and other VDR agonists exert a variety of antitumor effects on colon carcinoma cells, including inhibition of proliferation and invasiveness, sensitization to apoptosis, and inhibition of angiogenesis and metastasis (Pereira et al., 2012; Feldman et al., 2014; Ma et al., 2016) (Figure 3). In addition, 1,25(OH) ${ }_{2} \mathrm{D}_{3}$ inhibits the protumoral properties of CRC-associated fibroblasts and, accordingly, high VDR expression in these fibroblasts is associated with a favorable clinical outcome for metastatic CRC patients (Ferrer-Mayorga et al., 2016).

Mechanistically, these effects are based on regulation by $1,25(\mathrm{OH})_{2} \mathrm{D}_{3}$ of crucial genes controlling the cell cycle $\left(C D K N 1 A / \mathrm{p} 21^{\mathrm{CIP} 1}, C D K N 1 B / \mathrm{p} 27^{\mathrm{KIP} 1}\right.$, c-MYC, and others), apoptosis (BAX, and others), invasion (metalloproteases, and others), the epithelial-to-mesenchymal transition (CDH1/E-cadherin, and others) and angiogenesis. In addition, $1,25(\mathrm{OH})_{2} \mathrm{D}_{3}$ interferes with growth factor receptor-activated pathways, and antagonizes the $\mathrm{Wnt} / \beta$-catenin signaling pathway whose aberrant activation initiates and maintains CRC (Pereira et al., 2012; Larriba et al., 2013; Feldman et al., 2014; Larriba et al., 2016).

Further supporting a protective role of the vitamin D system against CRC, a number of studies have shown that it is disrupted at several levels in this neoplasia (and others). Although rarely mutated, VDR is downregulated in a relatively high proportion of advanced colorectal tumors, similarly to CYP27B1. Conversely, CYP24A1 is upregulated (Cross et al., 2001; Pálmer et al., 2004; Höbaus et al., 2016). 
Despite all these data suggesting that vitamin D has beneficial effects in CRC, results from interventional studies are unclear (Tagliabue et al., 2015). The few completed trials have limitations that make it difficult to draw conclusions, including low doses, short duration, false placebo groups, and a lack of adequate assessment of individual response. In addition, the optimal form of vitamin D to be administered and the most adequate treatment regimen still need to be defined. Contrarily, it has been proposed that CRC patients may have low serum 25(OH)D levels as a consequence of inadequate function of the vitamin D system due to the neoplastic process (the reverse causality hypothesis) (Autier et al., 2014). Against this, the coincident effects in terms of gene expression (increase in CYP27B1, CDKN1A/p21 ${ }^{\mathrm{CIP} 1}, B A X$ and $C D H 1 / \mathrm{E}$ cadherin, among others) that vitamin D has on normal colon tissue in a randomized, double-blind, placebo-controlled clinical trial and in preclinical studies strongly suggest that vitamin D has a protective, antitumor role in the human intestine (Bostick, 2015). Until new, well-designed, population-based studies and clinical trials have been carried out, it cannot be determined whether all these data form the basis for prevention strategies that avoid vitamin D deficiency and/or for the treatment of CRC patients with VDR agonists, preferentially in combination with other agents.

\section{Parallelism between the vitamin $D$ and thyroid hormone endocrine systems:}

\section{take-home lessons}

The regulatory action of $1,25(\mathrm{OH})_{2} \mathrm{D}_{3}$ in the organism has many similarities with that of thyroid hormone (3,5,3'-triodothyronine or $\left.\mathrm{T}_{3}\right)$. Both $1,25(\mathrm{OH})_{2} \mathrm{D}_{3}$ and $\mathrm{T}_{3}$ are pleiotropic hormones that have broad, crucial functions in a large number of tissues and organs and thus, are considered two of the main regulators of the physiology, homeostasis and development of higher organisms. They share a series of important 
features: both active hormones are synthesized stepwise in the organism from less active precursors $\left(1,25(\mathrm{OH})_{2} \mathrm{D}_{3}\right.$ from vitamin $\mathrm{D}_{3} /$ cholecalciferol and $25(\mathrm{OH}) \mathrm{D}_{3} ; \mathrm{T}_{3}$ from thyroxine or $\mathrm{T}_{4}$ ), and require an environmental element (solar radiation for cholecalciferol; iodine for $\mathrm{T}_{4}$ ). Their local concentration in target tissues is strictly controlled by intracellular enzymes that are responsible for their synthesis (CYP27B1; deiodinases 1 and 2) and degradation (CYP24A1; deiodinase 3).

Moreover, $1,25(\mathrm{OH})_{2} \mathrm{D}_{3}$ and $\mathrm{T}_{3}$ are major regulators of gene expression, by acting through members of the superfamily of nuclear receptors (VDR; thyroid receptors, TRs) that are highly homologous in structure and mode of activation. They function as ligand- and probably phosphorylation-modulated transcription factors forming heterodimers with RXR partner proteins. Both VDR and TRs were initially cloned from the avian genome during the 1980s (Sap et al., 1986; McDonnell et al., 1987) and, in agreement with the generalized effects of their ligands, are expressed in basically all cell types. VDR and TRs mediate the effects of their respective ligands on the transcription rate of their target genes. In addition, they also perform non-genomic actions consisting of a variety of rapid, transcription-independent modulatory effects on membrane ion channels and several types of cytoplasmic enzymes (kinases, phosphatases, and others) that eventually affect, overlap or are required for the regulation of nuclear gene expression (Ordonez-Moran et al., 2008; Davis et al., 2016; Flamant, 2016). In the case of $\mathrm{T}_{4} / \mathrm{T}_{3}$, non-genomic actions are mediated by truncated $\mathrm{TR}$ forms or by a hormone-binding site located in the plasma membrane integrin $\alpha_{\mathrm{v}} \beta_{3}$ (Davis et al., 2016). Notably, it was proposed that VDR and TRs interact physically (Schrader et al., 1994). However, the formation of such VDR-TR heterodimers was not confirmed in later studies. In fact, the common binding of the two receptors to the RXR partner support the possibility of sequestering/squelching, and therefore a competition 
between $1,25(\mathrm{OH})_{2} \mathrm{D}_{3}$ and $\mathrm{T}_{3}$ for the regulation of some target genes (Raval-Pandya et al., 1998).

Both hormones, $1,25(\mathrm{OH})_{2} \mathrm{D}_{3}$ and $\mathrm{T}_{3}$, ensure the adequate timing of expression of many genes during development and early life and in the homeostasis of many tissues in adult life. It is well-known that an insufficient level of thyroid hormone during development causes serious deficiencies (neurological cretinism and congenital hypothyroidism) that cannot usually be rescued by normalizing hormone levels later in life. This illustrates the crucial importance of this hormone at precise developmental stages. It is tempting to speculate that, analogously, adequate vitamin $\mathrm{D}$ status is essential for a series of events in tissue formation and physiology, perhaps already in early life, and that supplementation beyond a crucial period may be unable to normalize the physiology of affected tissues. Thus, one can hypothesize that supplementation cannot solve deficiencies and abnormalities caused by previous insufficiency in situations such as IBDs or CRC. Therefore, prevention may be more effective than the treatment of established disease in the case of these pathologies and perhaps others (i.e. multiple sclerosis), which may explain why the association between low levels of circulating 25(OH)D and a higher risk of CRC is not accompanied by clear positive effects of VDR agonists in population studies and clinical trials.

As expected from the coexpression of their respective receptors in many tissues, $1,25(\mathrm{OH})_{2} \mathrm{D}_{3}$ and $\mathrm{T}_{3}$ participate in the regulation of common processes, for instance myelination in the central nervous system (Bernal, 2007; de la Fuente et al., 2015). Likewise, the gut seems to be coregulated by both hormones, as together with the effects of vitamin D reviewed in previous sections, TRs are expressed in the gut (Plateroti et al., 1999) and $T_{3}$ controls intestinal development and functionality ((Sirakov and Plateroti, 2011; Sirakov et al., 2013) and references therein). Curiously, in 
contrast to what $1,25(\mathrm{OH})_{2} \mathrm{D}_{3}$ does in colon carcinoma cells, it has been proposed that $\mathrm{T}_{3}$ activates the $\mathrm{Wnt} / \beta$-catenin signaling pathway ((Sirakov et al., 2013) and references therein). If confirmed, this apparent opposite action of $1,25(\mathrm{OH})_{2} \mathrm{D}_{3}$ and $\mathrm{T}_{3}$ might represent effects under different situations or in response to distinct additional signals.

Regarding cancer, the overall homeostatic role of $1,25(\mathrm{OH})_{2} \mathrm{D}_{3}$ and $\mathrm{T}_{3}$ agrees with their inhibitory action on cell hyperproliferation, which is compatible with the promotion of proliferation of profoundly quiescent, serum-deprived cells or intestinal stem cells (van Leeuwen J. P. , 2011; Sirakov et al., 2013). In line with this, and with the fact that they promote differentiation of many cell types, both hormones are expected to protect against tumorigenesis and, concordantly, both hormonal systems are disturbed in malignancy (Feldman et al., 2014; Lin et al., 2016). Data on the relation of an altered thyroid hormone system (hypothyroidism or hyperthyroidism) and cancer are unclear and contradictory, as stimulation of cancer cell proliferation and tumorigenesis in animals has sometimes been reported, which may be related to $T_{4} / T_{3}$ binding to integrin $\alpha_{\mathrm{v}} \beta_{3}$ at the plasma membrane (Aranda et al., 2009; Sirakov and Plateroti, 2011; Davis et al., 2016; Lin et al., 2016).

$V D R$ and $T R$ genes are mutated at low frequency in human tumors, but alterations in their level of expression or in those of their ligands or transcriptional coregulators are relatively frequent. The highly important, pleiotropic nature of both endocrine systems supports the idea that their abnormal function may contribute to malignancy and, conversely, that tumorigenesis may alter their normal function. It seems reasonable that maintenance of the level of $1,25(\mathrm{OH})_{2} \mathrm{D}_{3}$ and $\mathrm{T}_{3}$ in the normal physiological range has protective effects in healthy individuals, and may contribute to better response of cancer patients to antitumor therapies. This may be particularly true 
in intestinal cancer, giving the broad, important homeostatic action of both hormones in this organ.

Conceivably, the long list of analogies between the vitamin $\mathrm{D}$ and thyroid endocrine systems is not serendipitous, but the result of efficient evolutionary selection. The existence of similar mechanisms of synthesis and degradation, elements (such as receptors) and mode of action for perhaps the two main regulatory systems in humans is remarkable and interesting. Particularly striking is their common dependence on external agents, UV radiation and iodine, respectively.

\section{Conclusions \& future perspectives}

The gut is a major target organ of vitamin $\mathrm{D}$, as shown by the expression of a high level of VDR in most cell types and the local synthesis of $1,25(\mathrm{OH})_{2} \mathrm{D}_{3}$. In addition to endocrine action, this is suggestive of intracrine, autocrine and paracrine actions of $1,25(\mathrm{OH})_{2} \mathrm{D}_{3}$. Indeed, $1,25(\mathrm{OH})_{2} \mathrm{D}_{3}$, and thus an appropriate vitamin $\mathrm{D}$ status, plays a crucial role in the control of gut homeostasis in experimental systems through an array of regulatory effects including calcium and phosphate absorption, maintenance of the epithelial barrier function, protection against infection, anti-inflammatory action and, probably, modulation of the gut microbiota. These effects result from regulation of the expression of a large number of target genes and signaling pathways and functions that they control in intestinal epithelial cells, fibroblasts and immune cells. In addition and in concordance with these actions, a deficient vitamin D system is associated with many abnormalities and a high risk of CRC, and protective effects of several VDR agonists against this neoplasia have been identified in preclinical settings. Future work is needed to elucidate how much of what we know about the actions of the vitamin D system in the gut can be translated to humans. Importantly, this includes the identification of effects on the differentiation and physiology of the several lineages of human intestinal 
cells and determination of the possibility of using vitamin D or any VDR agonist in the prevention and/or treatment of highly prevalent and serious diseases such as ulcerative colitis, Crohn's disease or CRC. To this purpose, large and well-designed, randomized trials using appropriate placebo groups and, ideally, proper analysis of individual sensitivity to VDR agonists (target genes, VDR polymorphisms) are desirable.

\section{Acknowledgements}

We thank Prof. Juan Bernal for his critical reading of the text and Lucille Banham for her valuable assistance in the preparation of the English manuscript. The work in the authors' laboratory is supported by the Ministerio de Economía y Competitividad of Spain-Fondo Europeo de Desarrollo Regional (FEDER) (SAF2016-76377-R) and the Instituto de Salud Carlos III-FEDER (RD12/0036/0021). 


\section{Figure legends}

Fig. 1. Diagram of the different types of actions of $1,25(\mathrm{OH})_{2} \mathrm{D}_{3}$ in the gut. Circulating $25(\mathrm{OH}) \mathrm{D}_{3}$ (nanomolar range) and $1,25(\mathrm{OH})_{2} \mathrm{D}_{3}$ (picomolar range) reach intestinal cells where the latter binds VDR and regulates the transcription of target genes (endocrine action). Intestinal cells express CYP27B1 that converts $25(\mathrm{OH}) \mathrm{D}_{3}$ into $1,25(\mathrm{OH})_{2} \mathrm{D}_{3}$, which can act within the synthesizing cell (intracrine action) or be secreted and act on the same cell (autocrine action) or on neighboring cells (paracrine action) as VDR is expressed in all cell types in the intestine.

Fig. 2. Diagram showing the main regulatory actions of $1,25(\mathrm{OH})_{2} \mathrm{D}_{3}$ in the small intestine and colon. Some diseases associated with dysfunction of the vitamin D system in the gut are depicted (in red).

Fig. 3. Mechanisms and cellular processes controlled by $1,25(\mathrm{OH})_{2} \mathrm{D}_{3}$ in the healthy gut and in colorectal cancer (CRC). 


\section{References}

Adams, J.S. and Hewison, M., 2008. Unexpected actions of vitamin D: new perspectives on the regulation of innate and adaptive immunity, Nat Clin Pract Endocrinol Metab. 4, 80-90.

Ananthakrishnan, A.N., Khalili, H., Higuchi, L.M., Bao, Y., Korzenik, J.R., Giovannucci, E.L., Richter, J.M., Fuchs, C.S. and Chan, A.T., 2012. Higher predicted vitamin D status is associated with reduced risk of Crohn's disease, Gastroenterology. 142, 482-9.

Aranda, A., Martínez-Iglesias, O., Rúiz-Llorente, L., García-Carpizo, V. and Zambrano, A., 2009. Thyroid receptor: roles in cancer, Trends Endocrinol Metab. 20, 318-24.

Assa, A., Vong, L., Pinnell, L.J., Rautava, J., Avitzur, N., Johnson-Henry, K.C. and Sherman, P.M., 2015. Vitamin D deficiency predisposes to adherent-invasive Escherichia coli-induced barrier dysfunction and experimental colonic injury, Inflamm Bowel Dis. 21, 297-306.

Autier, P., Boniol, M., Pizot, C. and Mullie, P., 2014. Vitamin D status and ill health: a systematic review, Lancet Diabetes Endocrinol. 2, 76-89.

Bao, B.Y., Yeh, S.D. and Lee, Y.F., 2006. 1alpha,25-dihydroxyvitamin D3 inhibits prostate cancer cell invasion via modulation of selective proteases, Carcinogenesis. 27, 32-42.

Beck, F., Chawengsaksophak, K., Waring, P., Playford, R.J. and Furness, J.B., 1999. Reprogramming of intestinal differentiation and intercalary regeneration in Cdx2 mutant mice, Proc Natl Acad Sci U S A. 96, 7318-23.

Bernal, J., 2007. Thyroid hormone receptors in brain development and function, Nat Clin Pract Endocrinol Metab. 3, 249-59.

Bonhomme, C., Duluc, I., Martin, E., Chawengsaksophak, K., Chenard, M.P., Kedinger, M., Beck, F., Freund, J.N. and Domon-Dell, C., 2003. The Cdx2 homeobox gene has a tumour suppressor function in the distal colon in addition to a homeotic role during gut development, Gut. 52, 1465-71.

Brabletz, T., Spaderna, S., Kolb, J., Hlubek, F., Faller, G., Bruns, C.J., Jung, A., Nentwich, J., Duluc, I., Domon-Dell, C., Kirchner, T. and Freund, J.N., 2004. Down-regulation of the homeodomain factor Cdx2 in colorectal cancer by collagen type I: an active role for the tumor environment in malignant tumor progression, Cancer Res. 64, 6973-7.

Brehier, A. and Thomasset, M., 1988. Human colon cell line HT-29: characterisation of 1,25-dihydroxyvitamin D3 receptor and induction of differentiation by the hormone, J Steroid Biochem. 29, 265-70.

Cai, G.H., Li, M.X., Lu, L., Yi Chan, R.L., Wang, J.H. and Cho, C.H., 2015. The current role and therapeutic targets of vitamin $\mathrm{D}$ in gastrointestinal inflammation and cancer, Curr Pharm Des. 21, 2917-23.

Cantorna, M.T., McDaniel, K., Bora, S., Chen, J. and James, J., 2014. Vitamin D, immune regulation, the microbiota, and inflammatory bowel disease, Exp Biol Med (Maywood). 239, 1524-30.

Ciubotaru, I., Green, S.J., Kukreja, S. and Barengolts, E., 2015. Significant differences in fecal microbiota are associated with various stages of glucose tolerance in African American male veterans, Transl Res. 166, 401-11.

Cross, H.S., Bareis, P., Hofer, H., Bischof, M.G., Bajna, E., Kriwanek, S., Bonner, E. and Peterlik, M., 2001. 25-Hydroxyvitamin $D_{3}-1 \alpha$-hydroxylase and vitamin D 
receptor gene expression in human colonic mucosa is elevated during early cancerogenesis, Steroids. 66, 287-92.

Chatterjee, B., Echchgadda, I. and Song, C.S., 2005. Vitamin D receptor regulation of the steroid/bile acid sulfotransferase SULT2A1, Methods Enzymol. 400, 165-91.

Chen, A., Davis, B.H., Bissonnette, M., Scaglione-Sewell, B. and Brasitus, T.A., 1999. 1,25-Dihydroxyvitamin $\mathrm{D}_{3}$ stimulates activator protein-1-dependent Caco-2 cell differentiation, J Biol Chem. 274, 35505-13.

Chen, J., Waddell, A., Lin, Y.D. and Cantorna, M.T., 2015. Dysbiosis caused by vitamin $\mathrm{D}$ receptor deficiency confers colonization resistance to Citrobacter rodentium through modulation of innate lymphoid cells, Mucosal Immunol. 8, 618-26.

Chen, S.W., Wang, P.Y., Zhu, J., Chen, G.W., Zhang, J.L., Chen, Z.Y., Zuo, S., Liu, Y.C. and Pan, Y.S., 2015. Protective effect of 1,25-dihydroxyvitamin d3 on lipopolysaccharide-induced intestinal epithelial tight junction injury in caco-2 cell monolayers, Inflammation. 38, 375-83.

Chen, Y., Du, J., Zhang, Z., Liu, T., Shi, Y., Ge, X. and Li, Y.C., 2014. MicroRNA-346 mediates tumor necrosis factor alpha-induced downregulation of gut epithelial vitamin D receptor in inflammatory bowel diseases, Inflamm Bowel Dis. 20, 1910-8.

Christakos, S., Dhawan, P., Verstuyf, A., Verlinden, L. and Carmeliet, G., 2016. Vitamin D: Metabolism, Molecular Mechanism of Action, and Pleiotropic Effects, Physiol Rev. 96, 365-408.

Davis, P.J., Goglia, F. and Leonard, J.L., 2016. Nongenomic actions of thyroid hormone, Nat Rev Endocrinol. 12, 111-21.

Davis, P.J., Glinsky, G.V., Lin, H.Y. and Mousa, S.A., 2016. Actions of Thyroid Hormone Analogues on Chemokines, J Immunol Res. 2016, 3147671.

de la Fuente, A.G., Errea, O., van Wijngaarden, P., Gonzalez, G.A., Kerninon, C., Jarjour, A.A., Lewis, H.J., Jones, C.A., Nait-Oumesmar, B., Zhao, C., Huang, J.K., ffrench-Constant, C. and Franklin, R.J., 2015. Vitamin D receptor-retinoid X receptor heterodimer signaling regulates oligodendrocyte progenitor cell differentiation, J Cell Biol. 211, 975-85.

Du, J., Chen, Y., Shi, Y., Liu, T., Cao, Y., Tang, Y., Ge, X., Nie, H., Zheng, C. and Li, Y.C., 2015. 1,25-Dihydroxyvitamin D Protects Intestinal Epithelial Barrier by Regulating the Myosin Light Chain Kinase Signaling Pathway, Inflamm Bowel Dis. 21, 2495-506.

Fan, J., Liu, S., Du, Y., Morrison, J., Shipman, R. and Pang, K.S., 2009. Up-regulation of transporters and enzymes by the vitamin D receptor ligands, 1alpha,25dihydroxyvitamin D3 and vitamin D analogs, in the Caco-2 cell monolayer, J Pharmacol Exp Ther. 330, 389-402.

Feldman, D., Krishnan, A.V., Swami, S., Giovannucci, E. and Feldman, B.J., 2014. The role of vitamin $\mathrm{D}$ in reducing cancer risk and progression, Nat Rev Cancer. 14, 342-57.

Ferrer-Mayorga, G., Gómez-López, G., Barbáchano, A., Fernández-Barral, A., Peña, C., Pisano, D.G., Cantero, R., Rojo, F., Muñoz, A. and Larriba, M.J., 2016. Vitamin $\mathrm{D}$ receptor expression and associated gene signature in tumour stromal fibroblasts predict clinical outcome in colorectal cancer, Gut.

Flamant, F., 2016. Futures Challenges in Thyroid Hormone Signaling Research, Front Endocrinol (Lausanne). 7, 58. 
Frank, D.N., St Amand, A.L., Feldman, R.A., Boedeker, E.C., Harpaz, N. and Pace, N.R., 2007. Molecular-phylogenetic characterization of microbial community imbalances in human inflammatory bowel diseases, Proc Natl Acad Sci U S A. $104,13780-5$.

Froicu, M., Weaver, V., Wynn, T.A., McDowell, M.A., Welsh, J.E. and Cantorna, M.T., 2003. A crucial role for the vitamin D receptor in experimental inflammatory bowel diseases, Mol Endocrinol. 17, 2386-92.

Fujita, H., Sugimoto, K., Inatomi, S., Maeda, T., Osanai, M., Uchiyama, Y., Yamamoto, Y., Wada, T., Kojima, T., Yokozaki, H., Yamashita, T., Kato, S., Sawada, N. and Chiba, H., 2008. Tight junction proteins claudin-2 and -12 are critical for vitamin D-dependent Ca2+ absorption between enterocytes, Mol Biol Cell. 19, 1912-21.

Fukumori, S., Murata, T., Taguchi, M. and Hashimoto, Y., 2007. Rapid and drastic induction of CYP3A4 mRNA expression via vitamin D receptor in human intestinal LS180 cells, Drug Metab Pharmacokinet. 22, 377-81.

Gao, N., White, P. and Kaestner, K.H., 2009. Establishment of intestinal identity and epithelial-mesenchymal signaling by Cdx2, Dev Cell. 16, 588-99.

Gaschott, T. and Stein, J., 2003. Short-chain fatty acids and colon cancer cells: the vitamin D receptor-butyrate connection, Recent Results Cancer Res. 164, 247-57.

Gilad, L.A., Tirosh, O. and Schwartz, B., 2006. Phytoestrogens regulate transcription and translation of vitamin D receptor in colon cancer cells, J Endocrinol. 191, 387-98.

Giloteaux, L., Goodrich, J.K., Walters, W.A., Levine, S.M., Ley, R.E. and Hanson, M.R., 2016. Reduced diversity and altered composition of the gut microbiome in individuals with myalgic encephalomyelitis/chronic fatigue syndrome, Microbiome. 4, 30.

Giovannucci, E., 2013. Epidemiology of vitamin d and colorectal cancer, Anticancer Agents Med Chem. 13, 11-9.

Golan, M.A., Liu, W., Shi, Y., Chen, L., Wang, J., Liu, T. and Li, Y.C., 2015. Transgenic Expression of Vitamin D Receptor in Gut Epithelial Cells Ameliorates Spontaneous Colitis Caused by Interleukin-10 Deficiency, Dig Dis Sci. 60, 1941-7.

Halline, A.G., Davidson, N.O., Skarosi, S.F., Sitrin, M.D., Tietze, C., Alpers, D.H. and Brasitus, T.A., 1994. Effects of 1,25-dihydroxyvitamin $\mathrm{D}_{3}$ on proliferation and differentiation of Caco-2 cells, Endocrinology. 134, 1710-7.

Höbaus, J., Tennakoon, S., Heffeter, P., Groeschel, C., Aggarwal, A., Hummel, D.M., Thiem, U., Marculescu, R., Berger, W. and Kallay, E., 2016. Impact of CYP24A1 overexpression on growth of colorectal tumour xenografts in mice fed with vitamin D and soy, Int J Cancer. 138, 440-50.

Jacobs, E.T., Kohler, L.N., Kunihiro, A.G. and Jurutka, P.W., 2016. Vitamin D and Colorectal, Breast, and Prostate Cancers: A Review of the Epidemiological Evidence, J Cancer. 7, 232-40.

Jahani, R., Fielding, K.A., Chen, J., Villa, C.R., Castelli, L.M., Ward, W.E. and Comelli, E.M., 2014. Low vitamin D status throughout life results in an inflammatory prone status but does not alter bone mineral or strength in healthy 3month-old CD-1 male mice, Mol Nutr Food Res. 58, 1491-501. 
Jin, D., Wu, S., Zhang, Y.G., Lu, R., Xia, Y., Dong, H. and Sun, J., 2015. Lack of Vitamin D Receptor Causes Dysbiosis and Changes the Functions of the Murine Intestinal Microbiome, Clin Ther. 37, 996-1009 e7.

Jones, M.L., Martoni, C.J. and Prakash, S., 2013. Oral supplementation with probiotic L. reuteri NCIMB 30242 increases mean circulating 25-hydroxyvitamin D: a post hoc analysis of a randomized controlled trial, J Clin Endocrinol Metab. 98, 2944-51.

Jurutka, P.W., Thompson, P.D., Whitfield, G.K., Eichhorst, K.R., Hall, N., Dominguez, C.E., Hsieh, J.C., Haussler, C.A. and Haussler, M.R., 2005. Molecular and functional comparison of 1,25-dihydroxyvitamin $\mathrm{D}_{3}$ and the novel vitamin $\mathrm{D}$ receptor ligand, lithocholic acid, in activating transcription of cytochrome P450 3A4, J Cell Biochem. 94, 917-43.

Kallay, E., Bareis, P., Bajna, E., Kriwanek, S., Bonner, E., Toyokuni, S. and Cross, H.S., 2002. Vitamin D receptor activity and prevention of colonic hyperproliferation and oxidative stress, Food Chem Toxicol. 40, 1191-6.

Kong, J., Zhang, Z., Musch, M.W., Ning, G., Sun, J., Hart, J., Bissonnette, M. and Li, Y.C., 2008. Novel role of the vitamin $D$ receptor in maintaining the integrity of the intestinal mucosal barrier, Am J Physiol Gastrointest Liver Physiol. 294, G208-16.

Krishnan, A.V. and Feldman, D., 2010. Molecular pathways mediating the antiinflammatory effects of calcitriol: implications for prostate cancer chemoprevention and treatment, Endocr Relat Cancer. 17, R19-38.

Kundu, R., Chain, B.M., Coussens, A.K., Khoo, B. and Noursadeghi, M., 2014. Regulation of CYP27B1 and CYP24A1 hydroxylases limits cell-autonomous activation of vitamin D in dendritic cells, Eur J Immunol. 44, 1781-90.

Kutuzova, G.D. and DeLuca, H.F., 2007. 1,25-Dihydroxyvitamin D3 regulates genes responsible for detoxification in intestine, Toxicol Appl Pharmacol. 218, 3744.

Larriba, M.J., García de Herreros, A. and Muñoz, A., 2016. Vitamin D and the Epithelial to Mesenchymal Transition, Stem Cells Int. 2016, 6213872.

Larriba, M.J., González-Sancho, J.M., Barbáchano, A., Niell, N., Ferrer-Mayorga, G. and Muñoz, A., 2013. Vitamin D Is a Multilevel Repressor of Wnt/b-Catenin Signaling in Cancer Cells, Cancers (Basel). 5, 1242-60.

Lee, S.M., Riley, E.M., Meyer, M.B., Benkusky, N.A., Plum, L.A., DeLuca, H.F. and Pike, J.W., 2015. 1,25-Dihydroxyvitamin D3 Controls a Cohort of Vitamin D Receptor Target Genes in the Proximal Intestine That Is Enriched for Calcium-regulating Components, J Biol Chem. 290, 18199-215.

Li, J., Jin, D., Fu, S., Mei, G., Zhou, J., Lei, L., Yu, B. and Wang, G., 2013. Insulin-like growth factor binding protein-3 modulates osteoblast differentiation via interaction with vitamin D receptor, Biochem Biophys Res Commun. 436, 632-7.

Lin, H.Y., Chin, Y.T., Yang, Y.C., Lai, H.Y., Wang-Peng, J., Liu, L.F., Tang, H.Y. and Davis, P.J., 2016. Thyroid Hormone, Cancer, and Apoptosis, Compr Physiol. 6, 1221-37.

Liu, W., Chen, Y., Golan, M.A., Annunziata, M.L., Du, J., Dougherty, U., Kong, J., Musch, M., Huang, Y., Pekow, J., Zheng, C., Bissonnette, M., Hanauer, S.B. and Li, Y.C., 2013. Intestinal epithelial vitamin D receptor signaling inhibits experimental colitis, J Clin Invest. 123, 3983-96. 
Liu, Y., Chen, L., Zhi, C., Shen, M., Sun, W., Miao, D. and Yuan, X., 2016. 1,25(OH)2D3 Deficiency Induces Colon Inflammation via Secretion of SenescenceAssociated Inflammatory Cytokines, PLoS One. 11, e0146426.

Liu, Z., Sun, B., Qi, L., Li, Y., Zhao, X., Zhang, D. and Zhang, Y., 2015. Dickkopf-1 expression is down-regulated during the colorectal adenoma-carcinoma sequence and correlates with reduced microvessel density and VEGF expression, Histopathology. 67, 158-66.

Ma, Y., Johnson, C.S. and Trump, D.L., 2016. Mechanistic Insights of Vitamin D Anticancer Effects, Vitam Horm. 100, 395-431.

Makishima, M., Lu, T.T., Xie, W., Whitfield, G.K., Domoto, H., Evans, R.M., Haussler, M.R. and Mangelsdorf, D.J., 2002. Vitamin D receptor as an intestinal bile acid sensor, Science. 296, 1313-6.

Mangin, M., Sinha, R. and Fincher, K., 2014. Inflammation and vitamin D: the infection connection, Inflamm Res. 63, 803-19.

Matsubara, T., Yoshinari, K., Aoyama, K., Sugawara, M., Sekiya, Y., Nagata, K. and Yamazoe, Y., 2008. Role of vitamin D receptor in the lithocholic acidmediated CYP3A induction in vitro and in vivo, Drug Metab Dispos. 36, 2058-63.

McCarthy, T.C., Li, X. and Sinal, C.J., 2005. Vitamin D receptor-dependent regulation of colon multidrug resistance-associated protein 3 gene expression by bile acids, J Biol Chem. 280, 23232-42.

McDonnell, D.P., Mangelsdorf, D.J., Pike, J.W., Haussler, M.R. and O'Malley, B.W., 1987. Molecular cloning of complementary DNA encoding the avian receptor for vitamin D, Science. 235, 1214-7.

Meckel, K., Li, Y.C., Lim, J., Kocherginsky, M., Weber, C., Almoghrabi, A., Chen, X., Kaboff, A., Sadiq, F., Hanauer, S.B., Cohen, R.D., Kwon, J., Rubin, D.T., Hanan, I., Sakuraba, A., Yen, E., Bissonnette, M. and Pekow, J., 2016. Serum 25hydroxyvitamin D concentration is inversely associated with mucosal inflammation in patients with ulcerative colitis, Am J Clin Nutr. 104, 113-20.

Meeker, S., Seamons, A., Maggio-Price, L. and Paik, J., 2016. Protective links between vitamin $\mathrm{D}$, inflammatory bowel disease and colon cancer, World J Gastroenterol. 22, 933-48.

Meeker, S., Seamons, A., Paik, J., Treuting, P.M., Brabb, T., Grady, W.M. and MaggioPrice, L., 2014. Increased dietary vitamin D suppresses MAPK signaling, colitis, and colon cancer, Cancer Res. 74, 4398-408.

Nakatsu, G., Li, X., Zhou, H., Sheng, J., Wong, S.H., Wu, W.K., Ng, S.C., Tsoi, H., Dong, Y., Zhang, N., He, Y., Kang, Q., Cao, L., Wang, K., Zhang, J., Liang, Q., Yu, J. and Sung, J.J., 2015. Gut mucosal microbiome across stages of colorectal carcinogenesis, Nat Commun. 6, 8727.

Obata, Y. and Pachnis, V., 2016. The Effect of Microbiota and the Immune System on the Development and Organization of the Enteric Nervous System, Gastroenterology.

Ooi, J.H., Li, Y., Rogers, C.J. and Cantorna, M.T., 2013. Vitamin D regulates the gut microbiome and protects mice from dextran sodium sulfate-induced colitis, J Nutr. 143, 1679-86.

Ordóñez-Morán, P., Larriba, M.J., Pálmer, H.G., Valero, R.A., Barbáchano, A., Dunach, M., de Herreros, A.G., Villalobos, C., Berciano, M.T., Lafarga, M. and Muñoz, A., 2008. RhoA-ROCK and p38MAPK-MSK1 mediate vitamin D effects on 
gene expression, phenotype, and Wnt pathway in colon cancer cells, J Cell Biol. 183, 697-710.

Pálmer, H.G., Sánchez-Carbayo, M., Ordóñez-Morán, P., Larriba, M.J., Cordón-Cardo, C. and Muñoz, A., 2003. Genetic signatures of differentiation induced by 1alpha,25-dihydroxyvitamin D3 in human colon cancer cells, Cancer Res. 63, 7799-806.

Pálmer, H.G., González-Sancho, J.M., Espada, J., Berciano, M.T., Puig, I., Baulida, J., Quintanilla, M., Cano, A., de Herreros, A.G., Lafarga, M. and Muñoz, A., 2001. Vitamin $\mathrm{D}(3)$ promotes the differentiation of colon carcinoma cells by the induction of E-cadherin and the inhibition of beta-catenin signaling, J Cell Biol. 154, 369-87.

Pálmer, H.G., Larriba, M.J., García, J.M., Ordóñez-Morán, P., Peña, C., Peiro, S., Puig, I., Rodríguez, R., de la Fuente, R., Bernad, A., Pollán, M., Bonilla, F., Gamallo, C., de Herreros, A.G. and Muñoz, A., 2004. The transcription factor SNAIL represses vitamin $\mathrm{D}$ receptor expression and responsiveness in human colon cancer, Nat Med. 10, 917-9.

Pereira, B., Sousa, S., Barros, R., Carreto, L., Oliveira, P., Oliveira, C., Chartier, N.T., Plateroti, M., Rouault, J.P., Freund, J.N., Billaud, M. and Almeida, R., 2013. CDX2 regulation by the RNA-binding protein MEX3A: impact on intestinal differentiation and stemness, Nucleic Acids Res. 41, 3986-99.

Pereira, F., Larriba, M.J. and Muñoz, A., 2012. Vitamin D and colon cancer, Endocr Relat Cancer. 19, R51-71.

Plateroti, M., Chassande, O., Fraichard, A., Gauthier, K., Freund, J.N., Samarut, J. and Kedinger, M., 1999. Involvement of T3Ralpha- and beta-receptor subtypes in mediation of T3 functions during postnatal murine intestinal development, Gastroenterology. 116, 1367-78.

Pulito, C., Terrenato, I., Di Benedetto, A., Korita, E., Goeman, F., Sacconi, A., Biagioni, F., Blandino, G., Strano, S., Muti, P., Mottolese, M. and Falvo, E., 2015. Cdx2 polymorphism affects the activities of vitamin $\mathrm{D}$ receptor in human breast cancer cell lines and human breast carcinomas, PLoS One. 10, e0124894.

Qin, J., Li, Y., Cai, Z., Li, S., Zhu, J., Zhang, F., Liang, S., Zhang, W., Guan, Y., Shen, D., Peng, Y., Zhang, D., Jie, Z., Wu, W., Qin, Y., Xue, W., Li, J., Han, L., Lu, D., Wu, P., Dai, Y., Sun, X., Li, Z., Tang, A., Zhong, S., Li, X., Chen, W., Xu, R., Wang, M., Feng, Q., Gong, M., Yu, J., Zhang, Y., Zhang, M., Hansen, T., Sanchez, G., Raes, J., Falony, G., Okuda, S., Almeida, M., LeChatelier, E., Renault, P., Pons, N., Batto, J.M., Zhang, Z., Chen, H., Yang, R., Zheng, W., Li, S., Yang, H., Wang, J., Ehrlich, S.D., Nielsen, R., Pedersen, O., Kristiansen, K. and Wang, J., 2012. A metagenome-wide association study of gut microbiota in type 2 diabetes, Nature. 490, 55-60.

Raval-Pandya, M., Freedman, L.P., Li, H. and Christakos, S., 1998. Thyroid hormone receptor does not heterodimerize with the vitamin $D$ receptor but represses vitamin D receptor-mediated transactivation, Mol Endocrinol. 12, 1367-79.

Ribiczey, P., Papp, B., Homolya, L., Enyedi, A. and Kovacs, T., 2015. Selective upregulation of the expression of plasma membrane calcium ATPase isoforms upon differentiation and 1,25(OH)2D3-vitamin treatment of colon cancer cells, Biochem Biophys Res Commun. 464, 189-94.

Ryz, N.R., Patterson, S.J., Zhang, Y., Ma, C., Huang, T., Bhinder, G., Wu, X., Chan, J., Glesby, A., Sham, H.P., Dutz, J.P., Levings, M.K., Jacobson, K. and Vallance, B.A., 2012. Active vitamin D (1,25-dihydroxyvitamin D3) increases host 
susceptibility to Citrobacter rodentium by suppressing mucosal Th17 responses, Am J Physiol Gastrointest Liver Physiol. 303, G1299-311.

Sap, J., Muñoz, A., Damm, K., Goldberg, Y., Ghysdael, J., Leutz, A., Beug, H. and Vennstrom, B., 1986. The c-erb-A protein is a high-affinity receptor for thyroid hormone, Nature. 324, 635-40.

Schrader, M., Muller, K.M., Nayeri, S., Kahlen, J.P. and Carlberg, C., 1994. Vitamin D3-thyroid hormone receptor heterodimer polarity directs ligand sensitivity of transactivation, Nature. 370, 382-6.

Schwab, M., Reynders, V., Loitsch, S., Steinhilber, D., Stein, J. and Schroder, O., 2007. Involvement of different nuclear hormone receptors in butyrate-mediated inhibition of inducible NF kappa B signalling, Mol Immunol. 44, 3625-32.

Schwartz, B., Smirnoff, P., Shany, S. and Liel, Y., 2000. Estrogen controls expression and bioresponse of 1,25-dihydroxyvitamin D receptors in the rat colon, Mol Cell Biochem. 203, 87-93.

Serrano, D., Gnagnarella, P., Raimondi, S. and Gandini, S., 2016. Meta-analysis on vitamin D receptor and cancer risk: focus on the role of TaqI, ApaI, and Cdx2 polymorphisms, Eur J Cancer Prev. 25, 85-96.

Sirakov, M. and Plateroti, M., 2011. The thyroid hormones and their nuclear receptors in the gut: from developmental biology to cancer, Biochim Biophys Acta. 1812, 938-46.

Sirakov, M., Skah, S., Nadjar, J. and Plateroti, M., 2013. Thyroid hormone's action on progenitor/stem cell biology: new challenge for a classic hormone?, Biochim Biophys Acta. 1830, 3917-27.

Sun, J., Mustafi, R., Cerda, S., Chumsangsri, A., Xia, Y.R., Li, Y.C. and Bissonnette, M., 2008. Lithocholic acid down-regulation of NF-kappaB activity through vitamin D receptor in colonic cancer cells, J Steroid Biochem Mol Biol. 111, 37-40.

Tachibana, S., Yoshinari, K., Chikada, T., Toriyabe, T., Nagata, K. and Yamazoe, Y., 2009. Involvement of Vitamin D receptor in the intestinal induction of human ABCB1, Drug Metab Dispos. 37, 1604-10.

Tagliabue, E., Raimondi, S. and Gandini, S., 2015. Vitamin D, Cancer Risk, and Mortality, Adv Food Nutr Res. 75, 1-52.

Tao, Q., Wang, B., Zheng, Y., Jiang, X., Pan, Z. and Ren, J., 2015. Vitamin D prevents the intestinal fibrosis via induction of vitamin $\mathrm{D}$ receptor and inhibition of transforming growth factor-beta1/Smad3 pathway, Dig Dis Sci. 60, 868-75.

van Harten-Gerritsen, A.S., Balvers, M.G., Witkamp, R.F., Kampman, E. and van Duijnhoven, F.J., 2015. Vitamin D, Inflammation, and Colorectal Cancer Progression: A Review of Mechanistic Studies and Future Directions for Epidemiological Studies, Cancer Epidemiol Biomarkers Prev. 24, 1820-8.

van Leeuwen J. P. , M., Feldman David, Muñoz Alberto 2011. Vitamin D: Cancer and Differentation, in: David Feldman, J.W.P.a.J.S.A. (Ed.), Vitamin D (Third Edition). Elsevier Inc.

Veldman, C.M., Cantorna, M.T. and DeLuca, H.F., 2000. Expression of 1,25dihydroxyvitamin $\mathrm{D}(3)$ receptor in the immune system, Arch Biochem Biophys. 374, 334-8.

Wada, K., Tanaka, H., Maeda, K., Inoue, T., Noda, E., Amano, R., Kubo, N., Muguruma, K., Yamada, N., Yashiro, M., Sawada, T., Nakata, B., Ohira, M. and Hirakawa, $\mathrm{K}$., 2009. Vitamin D receptor expression is associated with colon cancer in ulcerative colitis, Oncol Rep. 22, 1021-5. 
Wu, S., Yoon, S., Zhang, Y.G., Lu, R., Xia, Y., Wan, J., Petrof, E.O., Claud, E.C., Chen, D. and Sun, J., 2015. Vitamin D receptor pathway is required for probiotic protection in colitis, Am J Physiol Gastrointest Liver Physiol. 309, G341-9.

Wu, S., Zhang, Y.G., Lu, R., Xia, Y., Zhou, D., Petrof, E.O., Claud, E.C., Chen, D., Chang, E.B., Carmeliet, G. and Sun, J., 2015. Intestinal epithelial vitamin D receptor deletion leads to defective autophagy in colitis, Gut. 64, 1082-94.

Yamamoto, H., Miyamoto, K., Li, B., Taketani, Y., Kitano, M., Inoue, Y., Morita, K., Pike, J.W. and Takeda, E., 1999. The caudal-related homeodomain protein $\mathrm{Cdx}-2$ regulates vitamin $\mathrm{D}$ receptor gene expression in the small intestine, $\mathrm{J}$ Bone Miner Res. 14, 240-7.

Yang, L., Weaver, V., Smith, J.P., Bingaman, S., Hartman, T.J. and Cantorna, M.T., 2013. Therapeutic effect of vitamin $d$ supplementation in a pilot study of Crohn's patients, Clin Transl Gastroenterol. 4, e33.

Yu, S., Bruce, D., Froicu, M., Weaver, V. and Cantorna, M.T., 2008. Failure of T cell homing, reduced CD4/CD8alphaalpha intraepithelial lymphocytes, and inflammation in the gut of vitamin D receptor KO mice, Proc Natl Acad Sci U S A. 105, 20834-9.

Yu, X.P., Bellido, T. and Manolagas, S.C., 1995. Down-regulation of NF-kappa B protein levels in activated human lymphocytes by 1,25-dihydroxyvitamin D3, Proc Natl Acad Sci U S A. 92, 10990-4.

Zator, Z.A., Cantu, S.M., Konijeti, G.G., Nguyen, D.D., Sauk, J., Yajnik, V. and Ananthakrishnan, A.N., 2014. Pretreatment 25-hydroxyvitamin D levels and durability of anti-tumor necrosis factor-alpha therapy in inflammatory bowel diseases, JPEN J Parenter Enteral Nutr. 38, 385-91.

Zhao, H., Zhang, H., Wu, H., Li, H., Liu, L., Guo, J., Li, C., Shih, D.Q. and Zhang, X., 2012. Protective role of $1,25(\mathrm{OH}) 2$ vitamin D3 in the mucosal injury and epithelial barrier disruption in DSS-induced acute colitis in mice, BMC Gastroenterol. $12,57$. 